УДК 1:316

DOI: $10.18101 / 1994-0866-2019-4-50-56$

\title{
РОЛЬ И ЗНАЧЕНИЕ КОГНИТИВНОГО МЕНЕДЖМЕНТА В ТРАНСФОРМАЦИИ СТРАТЕГИИ УПРАВЛЕНИЯ ГОРОДОМ: К ПОСТАНОВКЕ ПРОБЛЕМЫ
}

\author{
(C) Галимова Алевтина Сергеевна \\ аспирант, \\ Томский политехнический университет \\ Россия, 634050, г. Томск, пр-т Ленина, 30 \\ E-mail: alevtinab94@gmail.com
}

В статье описана сущность общества знаний, которое рассматривается в качестве общества организаций. В этой связи современное городское управление в новом знаниевом обществе является сложной организационной структурой, где город представлен как фабрика знаний. Когнитивный менеджмент предложен в качестве стратегии управления, которая соответствует новым изменениям. Указаны причины применения когнитивного подхода в современной городской управленческой практике, рассмотрены основные принципы, выделены главные области когнитивного менеджмента, раскрыта их роль в управлении современным городом. Даны понятия экспертного знания и научающейся организации, обозначена роль экспертизы и экспертной оценки в управлении городом. Обоснована и доказана необходимость применения когнитивного подхода в современной городской управленческой практике.

Ключевые слова: общество знания; когнитивный менеджмент; общество организаций; городское управление; сложная организационная структура; научающиеся организации; экспертное знание; экспертная оценка.

\section{Для цитирования}

Галимова А. С. Роль и значение когнитивного менеджмента в трансформации стратегии управления городом: к постановке проблемы // Вестник Бурятского государственного университета. Философия. 2019. Вып. 4. С. 50-56.

Во второй половине $\mathrm{XX}$ в. аналитики заговорили о переходе к обществу знания, где знание становится драйвером развития. В конститутивную особенность modus vivendi превращена обнаружившая себя служебность знания обществу. $\mathrm{C}$ использованием знания формируются релевантные механизмы управления обществом знания, в числе этих механизмов - когнитивный менеджмент; сущность этой инновационной управленческой стратегии заключена в управлении массивами тех знаний, которые существуют в обществе, а также в управлении изменениями посредством имеющихся знаний. Термин «управленческая стратегия», используемый в современной теории управления, необходим для своевременного и адекватного воздействия на объект управления, за которым возможно увидеть перспективу развития общества. Выбор стратегии управления чрезвычайно важен (в основании его лежит стремление сделать управленческое воздействие максимально эффективным) и должен быть ресурсно обеспеченным. Таким ресурсом в обществе знания является знание, обретшее статус источника развития социальной и культурной сферы.

Проблемы когнитивного менеджмента требуют четкого разграничения таких понятий, как дата (data), информация (information), знания (knowledge). Данные (в 
A. С. Галимова. Роль и значение когнитивного менеджмента в трансформации стратегии управления городом: к постановке проблемы

интерпретации Д. У. Делонга и Л. Фейха) - это необращенные или несокращенные познания прошлых, настоящих и будущих событий; информация воплощена в моделях, представленных в данных; знание - ресурс, определяемый контекстом и заключенный в сложившейся практике. Знание, воплощаясь в языке, превращено в могущественный фактор принятия решений.

В обществе знания классическим факторам производства (капитал, труд, земля) по-прежнему отведена важная роль, но постепенно они начинают отходить на второй план, по причине того, что в новом обществе обладателю специализированных, профессиональных знаний их приобретение не является сложной задачей. Важным для понимания, по мнению П. Дракера, является то, «что само по себе специализированное знание ничего не производит, оно приносит пользу только при интеграции с какой-либо задачей. Именно поэтому общество знаний выступает так же, как общество организаций $[1$, с. 3]. В таком обществе цель и функция любой организации, деловой или некоммерческой, есть включение специальных знаний в рамках единой задачи [1].

Так, следуя логике рассуждения П. Дракера, мы можем говорить о том, «что современное городское управление можно рассматривать как сложную организационную структуру, функция которой - заставить знания работать над инструментами, продуктами и процессами, над проектированием работы; над знаниями как таковыми» $[1$, c. 4]. Потому что природа знания заключается в его непостоянстве, изменчивости - то, что сегодня является бесспорным, завтра может стать абсурдом.

По мнению Е. Р. Метелевой, «город - это сложная структура, включающая экономическую, социальную, географическую, градостроительную системы, которые могут быть увязаны между собой только в "замыкающейся" предельной рамке управленческого видения, управленческого мышления» [2].

В современных исследованиях город часто предстает как фабрика знаний, поскольку сегодня интеллектуальный и человеческий капиталы выходят на передний план в роли основных факторов развития. Кроме того, само знание имеет крайне нехарактерную динамику формирования, оно находится в постоянном изменении, развитии, нестабильности, что требует особых управленческих решений и действий [3]. Все это создает необходимость в изменении управленческих стратегий современного города [4]. Такой управленческой стратегией является когнитивный менеджмент - стратегия управления, появившаяся в ответ на формирующееся новое знаниевое общество. Она основана на распространении и обмене знаниями в организации и за ее пределами, применении знаний в деятельности организации и принятии решений на базе этих знаний, производстве товаров, продуктов, услуг, документов [5].

В области городского управления особо трудоемким является анализ процессов функционирования различных городских систем, таких как транспорт, экология, экономика и др., поскольку именно человек находится в центре всех этих процессов. Данное обстоятельство является предпосылкой к применению когнитивного подхода в городской управленческой практике. Кроме этого, многоаспектность и взаимосвязанность происходящих процессов в этих областях также оказывают влияние на городское управление [6].

Итак, по словам П. Дракера, «для менеджеров динамика знаний выдвигает один ясный императив: каждая организация должна встроить систему управления 
изменениями непосредственно в свою структуру» [1]. Раскроем смысл данного утверждения.

Во-первых, к чему должна быть готова любая компания, — это отказаться от своей сегодняшней деятельности в пользу нового. Она должна приучить себя через определенный промежуток времени задавать себе вопросы о своей деятельности, политике или какой-либо процедуре и т. д. Например, «если бы мы еще не делали того, что мы делаем сейчас, стали бы делать это, зная то, что мы знаем сейчас?». Если ответом на этот вопрос будет «нет», то организация должна спросить себя: «Так что же нам делать сейчас?» И обязательно нужно сделать что-то новое, а не предлагать провести очередное исследование. Кроме этого, организация должна быть готова отказаться от шанса продлить свое существование в профессиональной сфере. Отказ от удачной, прибыльной практики должен стать одним из пунктов в долгосрочном планировании [1].

И, во-вторых, любая организации во главу угла должна поставить процесс создания чего-то принципиально нового, т. е. сделать это главной целью. Для этого, по мнению П. Дракера, организация должна внедрить в свою деятельность три регулярные практики:

1) постоянное совершенствование своей деятельности. В Японии данный принцип называется кайзен (kaizen) - улучшение продукта или услуги с целью получения каждые два-три года совершенно другого продукта или услуги;

2) умение использовать свои знания. Организации необходимо на основе своих прошлых достижений научиться создавать что-то принципиально новое;

3) умение генерировать инновации. Данный процесс обязательно должен быть систематическим. Организация должна быть готова в любой момент отказаться от всего, что уже смогла достичь или создать, и начать процесс заново [1].

Таким образом, если организация, которая функционирует в обществе знания, будет пренебрегать вышеупомянутыми тремя практиками, она рискует отстать от новейших трендов в своей области, потерять производительность и, как следствие, стать непривлекательной для высококвалифицированных и образованных сотрудников, которые играют доминирующую роль в обществе знания.

Также существует еще один аспект, который представляется особенно важным для города как организационной структуры. Организации необходимо отказаться от централизованной системы управления, т. к. процесс быстрого и эффективного принятия решений требует полной децентрализации. Все решения должны базироваться на знаниях различных отделов (окружающая среда, демографическая, экономическая, экологическая ситуация и т. д.). Все знания, которые способствуют появлению инновации, должны быть вовремя обнаружены и использованы [1].

Итак, городскому управлению как организационной структуре для успешного ведения своей деятельности в обществе знания необходимо не только уметь работать с уже имеющимся знаниями в организации, но и создавать новые знания посредством постоянного научения. Здесь мы говорим о таком понятии, введенным Д. А. Гарвином, как научающиеся организации, которые умеют создавать, приобретать и распространять знание и изменять свое поведение в соответствии с новым знанием и пониманием [7]. Такие организации, по мнению ученого, обладают набором следующих видов деятельности: 
A. С. Галимова. Роль и значение когнитивного менеджмента в трансформации стратегии управления городом: к постановке проблемы

1. «Систематическое решение проблем - базируется на философии управления качеством и методах данной дисциплины (диагностика проблемы, опирающаяся на научные методы, принятие решений с опорой на факты, систематизация данных и выводов).

2. Экспериментирование - постоянный поиск нового знания и его проверка.

3. Научение на прошлом опыте - рефлексия на свои успехи и ошибки, их систематическая оценка и представление в виде уроков.

4. Научение на чужом опыте - иногда бесконечным источником идей могут быть компании, ведущие свою деятельность совершенно в иной сфере.

5. Передача знаний - чтобы научение коснулось каждого отдела в организации, знания должны распространяться быстро, эффективно и без преград» [7].

По словам Д. А. Гарвина: «Если компании ничему не учатся, они - как и индивидуумы - просто повторяют пройденное. Изменения носят косметический характер, а улучшения или случайны, или недолговечны» [7, с. 109].

Д. А. Гарвин выделяет несколько начальных шагов, которые помогут в создании научающейся организации. Во-первых, нужно создать такую среду, где научение будет само собой разумеющимся. Организации необходимо выделить время для размышления и анализа, обдумывания будущей стратегии, анализа потребностей потребителей и т. д. Во-вторых, необходимо устранить всевозможные границы между отделами организации и активно поощрять обмен идеями. В-третьих, после создания благоприятной среды для научения нужно создавать открытые площадки для научения, например, слеты, симпозиумы, учебные поездки [7].

Итак, когнитивный менеджмент включает в себя работу не только с уже имеющимся знанием, но и работу над созданием нового знания через постоянное научение. Н. М. Абдикеев в своей работе выделяет следующие принципы когнитивного менеджмента в системе организационного научения:

- «знание возникает и находится в умах людей;

- в основе совместного использования знаний находится доверие;

- поддержка и вознаграждение совместного использования знаний;

- управленческая поддержка и дополнительные ресурсы обязательны;

- пилотные программы должны предварять инициативы по использованию знаний;

- оценка инициатив при помощи количественных и качественных показателей;

- знание - продукт творчества, поэтому его необходимо постоянно поощрять для развития в различных направлениях» [6].

Таким образом, можем выделить основные моменты когнитивного менеджмента - это непрерывная работа с уже имеющимися знаниями в организации, постоянное обучение на основе различного опыта, а также управление процессами, которые позволяют это знание распознать, аккумулировать, распределить и использовать.

Поскольку в центре всех городских управленческих процессов находятся люди, необходимо сказать о важности экспертного знания, которое является разновидностью специального знания. В первую очередь данный вид знания появляется в социальной и научно-технической сферах. Именно такое знание, как правило, является важнейшим при принятии важных, авторитетных решений [8]. По 
словам Н. П. Лукиной: «Для разрешения разного рода проблемных ситуаций требуется обращение к специализированному профессиональному знанию, т. е. экспертному знанию, каким обладают - в силу их образования и опыта — лишь немногие, вполне определенные люди - эксперты» [8].

В знаниевом обществе успех организации напрямую зависит от ее интеллектуальных возможностей. Профессиональный интеллект, экспертное знание представляют одну из важнейших составляющих успеха организации. Например, корпорация Microsoft приглашает на собеседование огромное количество перспективных кандидатов, прежде чем отобрать самого лучшего разработчика для будущего программного обеспечения [9].

Одним из ярких примеров успешного применения экспертного знания в городском управлении является создание властями Рио-де-Жанейро «Компании городского развития региона Порта Рио-де-Жанейро» во время строительства «Музея будущего». Появление данного музея обязано летним Олимпийским играм в Бразилии. Организаторами было принято решение разместить будущий музей в одном из самых неблагополучных районов города - на заброшенном пирсе. Так, благодаря совместным усилиям городского управления и главного архитектора Сантьяго Калатравы на этом месте появился музей, который признан одним из самых «зеленых» зданий в мире, а в первый день открытия он проработал без перерыва 32 часа из-за большого количества посетителей.

Во время строительства данного сооружения власти понимали, что появление такого масштабного проекта изменит ритм, быт, инфраструктуру района. Было принято решение о привлечении городских экспертов и создании «Компании городского развития региона Порта Рио-де-Жанейро», которая на протяжении четырех лет занималась развитием района. Экспертами был проведен глубокий анализ сохранившихся на данной территории памятников, далее были проведены работы по их восстановлению. Кроме этого, компания развития региона проводила комплексную работу по адаптации местного населения к грядущим переменам. Отличной иллюстрацией проделанной работы служат слова исполнительного директора музея Оливейры: «Но самое прекрасное то, что раньше у меня не было ни одного повода прийти в этот район. Даже при том, что я родился здесь 50 лет назад, я бы не пошел сюда гулять. А теперь каждый четверг я отправляюсь сюда с людьми из нашего офиса съесть на бизнес-ланч пиццу или что-то такое. Мы сидим за столом, смотрим на старые здания, на памятники рабам и правителям, и это так мило...».

Итак, история данного места является ярким примером грамотного применения экспертного знания при решении городских задач. Благодаря качественно проделанной работе «Компании городского развития региона Порта Рио-де-Жанейро» ранее неблагополучный район сегодня является одним из самых посещаемых мест в городе. Это говорит о важности и доминирующей роли экспертного знания при принятии различных решений по управлению и развитию городом.

Таким образом, в городском управлении применение принципов когнитивного менеджмента представляется особенно важным, потому что городская среда, как и само знание, находится под действием постоянных изменений. Важно еще раз подчеркнуть, что в центре всех городских управленческих процессов находятся люди. Именно поэтому умение аккумулировать, перерабатывать и грамотно 
A. С. Галимова. Роль и значение когнитивного менеджмента в трансформации стратегии управления городом: к постановке проблемы

использовать знания представляется одним из самых важных моментов в городском управлении как сложной организационной структуре для успешного функционирования системы в обществе знания.

\title{
Лuтература
}

1. Дракер П. Ф. Новое общество организаций // Управление знаниями: хрест. / пер. с англ.; под ред. Т. Е. Андреевой, Т. Ю. Гутниковой. СПб.: Изд-во Высш. шк. менеджмента, 2009. С. $2-18$.

2. Метелева Е. Р. Уточнение содержания понятий «город», «городское развитие» и «управление городским развитием» // Известия ИГЭА. 2011. № 3(77). С. 160-164.

3. Корниенко А. А. Когнитивный менеджмент как инновационная стратегия управления в обществе знания: концептуальный аспект // Вестник Томского государственного университета. Философия. Социология. Политология. 2016. № 3. С. 36-45.

4. Ермоленко В. В., Ланская Д. В. Чугунова Н. А. Модели города в условиях экономики знаний // Политематический сетевой электронный научный журнал Кубанского государственного аграрного университета. 2016. № 4(118). С. 1671-1692.

5. Стаховская Ю. М. Теоретические принципы построения системы когнитивного менеджмента // Вестник Томского государственного университета. 2009. № 327. С. 59-61.

6. Абдикеев Н. М. Когнитивный менеджмент // Управление знаниями. 2014. № 3. C. $71-78$.

7. Гарвин Д. А. Создание научающейся организации // Управление знаниями / пер. с англ. под ред. Т. Е. Андреевой, Т. Ю. Гутниковой; Высшая школа менеджмента СПбГУ. СПб.: Изд-во Высш. шк. менеджмента, 2009. 514 с.

8. Лукина Н. П. Эпистемологический статус экспертного знания в когнитивном пространстве информационного общества // Гуманитарная информатика. 2009. № 5 [Электронный ресурс]. URL: http://journals.tsu.ru/uploads/import/ 1163/files/lukina5.pdf (дата обращения: 20.07.2019).

9. Куинн Дж. Б., Андерсон Ф., Финкельштейн С. Управление профессиональным интеллектом: использовать лучшее по максимуму //Управление знаниями / пер. с англ. под ред. Т. Е. Андреевой, Т. Ю. Гутниковой; СПб.: Высшая школа менеджмента, 2009. 514 с.

10. Мировой опыт: музей будущего в заброшенном порту Рио-де-Жанейро [Электронный ресурс]. URL: https://strelka.com/ru/magazine/2017/06/28/museu-do-amanh (дата обращения: 20.07.2019).

\section{ROLE AND SIGNIFICANCE OF COGNITIVE MANAGEMENT IN TRANSFORMATION OF THE CITY GOVERNANCE STRATEGY: A PROBLEM STATEMENT}

\author{
Alevtina S. Galimova \\ Research Assistant, \\ Tomsk Polytechnic University \\ 30 Lenina Prospect, Tomsk 634050, Russia \\ E-mail: alevtinab94@gmail.com
}

The article deals with the essence of knowledge society, which is considered as a society of organizations. In this regard, modern municipal governance in the new knowledge society is a complex organizational structure, where the city is represented as a factory of knowledge. In view of this, we have proposed cognitive management as a management strategy that is in line with new changes. The article highlights the reasons for applying the 
cognitive approach in modern municipal governance, the basic principles and key propriety areas of cognitive management, its role in managing a modern city. We have considered the concepts of expert knowledge and learning organization, the role of expertise and expert assessment in municipal governance, and proved the necessity of the cognitive approach application in modern city management.

Keywords: knowledge society; cognitive management; society of organizations; municipal governance; complex organizational structure; learning organizations; expert knowledge; expert assessment. 